\title{
Depressive symptoms and associated factors among public high school students in Bahir Dar City, Northwest Ethiopia: A cross-sectional study
}

Debela Tarecha ( $\square$ debelatarecha2016@gmail.com )

Department of psychiatry, College of health sciences, Mettu University, Mettu, Ethiopia

\section{Tesfa Mekonen}

National Centre for Youth Substance Use Research, The University of Queensland, Australia

Gizachew Asnake

Department of psychiatry, College of medicine and Health Sciences, Bahir Dar University, Bahir Dar, Ethiopia

Hunde Tarafa

Department of psychiatry, College of health sciences, Mettu University, Mettu, Ethiopia

\section{Research Article}

Keywords:

Posted Date: February 23rd, 2022

DOI: https://doi.org/10.21203/rs.3.rs-1382396/v1

License: (c) (1) This work is licensed under a Creative Commons Attribution 4.0 International License. Read Full License 


\section{Abstract}

Background: Depression is the most prevalent mental disorder in adolescents that lead to educational impairment, substance use problems, and suicidal attempts. The aim of this study was to assess depressive symptoms and their associated factors among public high school students in Bahir Dar city, Northwest Ethiopia.

Methods: An institution-based cross-sectional study was conducted from March to April 2021 at Bahir Dar City public high school students. Data were collected from 781 participants using a self-administered questionnaire. Participants were selected using the multistage sampling method. Patient health questionnaire 9 modified for adolescents (PHQ-9A) was used to measure depressive symptoms. Data were analyzed using Statistical Package for Social Sciences (SPSS) version 25. Logistic regression analysis was done to identify factors associated with depressive symptoms. Variables with P-value $<0.05$ were considered statistically significant.

Result: The prevalence of depressive symptoms were found to be $19.7 \%(\mathrm{Cl}=16.9,22.6)$. Depressive symptoms were significantly associated with female sex (AOR=2.36, 95\% $\mathrm{Cl}=1.54-3.61)$, having known medical conditions ( $A O R=1.85,95 \% \mathrm{Cl}=1.03-3.31)$, poor social support $(A O R=1.83,95 \% \mathrm{Cl}=1.03-3.31)$, childhood abuse (AOR=2.02, 95\% $\mathrm{Cl}=1.28-3.20)$ and neglect $(\mathrm{AOR}=2.78,95 \% \mathrm{Cl}=1.70-4.55)$, and occupation of mother $(\mathrm{AOR}=0.38 \mathrm{Cl}=0.15-0.95)$.

Conclusions: One in five public high students reported depressive symptoms. Schools need to institute routine mental health screening services and implement appropriate interventions to initiate and improve access to school-based mental health services, particularly for female students.

\section{Introduction}

Adolescence is the peak age of onset for depression disorder (1). The transition period from childhood to adulthood is particularly a stage marked by emotional instability that makes adolescents vulnerable to depression (2). Half of all mental health conditions start at 14 years of age but most cases are undetected and untreated (3). Early depression especially persistent childhood/adolescent depressive symptoms have robust, lasting associations with adult functioning (4). Early intervention may reduce the long-term burden of disease (5). Approximately $60.1 \%$ of adolescents with major depressive episodes did not receive treatment (6). World Health Organization (WHO) identified depression as a priority mental health disorder of adolescence because of its high prevalence and associated disabilities, including increased risk of suicide $(5,7,8)$. Depression is also one of the leading causes of illness and disability among adolescents (9).

The lifetime prevalence of major depression in adolescence is $15-20 \%$ globally (10). In the USA, the prevalence of major depressive episodes was higher among adolescent females (20.0\%) compared to males (6.8\%) (11). A systematic review done on the prevalence of mental health problems in sub-Saharan adolescents showed that the median point prevalence of depression among adolescents is $26.9 \%(12)$. 
The strongest risk factors contributing to depression in adolescents are a family history of depression and exposure to psychosocial stress, inherited risks, developmental factors, sex hormones, and psychosocial adversity interact to increase risk through hormonal factors and associated perturbed neural pathways (7). Understanding the risk factors of depressive symptoms is a vital first step in contributing to planning preventive and control strategies (13). However, evidence on the magnitude and associated factors of depressive symptoms among high school students is scarce in Ethiopia (14-18). Therefore, the purpose of this study was to determine the magnitude of depressive symptoms and their associated factors among public high school students.

\section{Material And Methods}

\section{Study design and setting}

An institutional-based cross-sectional study was conducted from March to April 2021 at Bahir Dar City, Northwest Ethiopia. Bahir Dar city is located in Northwestern Ethiopia and is the 3rd largest city in Ethiopia. The city has an estimated population of 170,000 . Bahir Dar is the capital city of the Amhara Regional State. The city is located $578 \mathrm{~km}$ far apart from Addis Ababa and has an elevation of $1840 \mathrm{~m}$ above sea level. Bahir Dar city administration is divided into six administrative sub-cities. Regarding Education services, the city comprises eleven public high schools with a total number of students 23,316 in the academic year of 2020/2021.

\section{Source populations and study populations}

All regular public high school students in Bahir Dar City were the source of the population. The study populations were all selected students in the three selected public high schools.

\section{Sample size and sampling procedure}

The sample size was calculated using a single population proportion formula considering $36.2 \%$ depression (17), 95\% confidence interval, $5 \%$ margin of error, 2 design effects, and $10 \%$ non-response rate. The final sample size was 781. A multistage sampling technique was used to select participants. In the first stage, three schools were selected from eleven public high schools by lottery method. In the second stage, students of the selected public high schools were categorized into grade levels from 9th to 12th separately. The sampling frame of students in each of the grade levels and sections was obtained from the academic director offices of schools.

Then the students were stratified according to their grade level and sections. The sample sizes were distributed to each grade and section proportionally according to the class size of the grade level. Finally, students were chosen from each grade level 9th - 12th and section using a simple random sampling technique (see Fig. 1 below).

\section{Study variables}


The dependent variable was depressive symptoms among public high school students (yes/no). Independent variables included were socio-demographic factors (age, sex, level of grade, living status, residence, educational status of the father, educational status of the mother, occupation of the father, occupation of the mother, parental marital status); psycho-social factors (adverse childhood experience, social support); health-related factors (family history of mental illness, having known medical illness); substance-related factors (alcohol use, khat use, tobacco use, and marijuana use).

\section{Data collection and measurement tools}

Data were collected by self-administered questionnaire consisting socio-demographic factors, patient health questioner modified for adolescent (PHQ-9A), adverse childhood experience (ACEs), clinical features, social support, substance use assessment, and academic stressors. Depressive symptoms were assessed by Patient health questionnaire 9 modified for adolescents (PHQ-9A), a self-report instrument comprised of 9-items. Items are rated on a four-point ordinal scale. The total PHQ-9A score for each respondent was calculated by adding all 9 items and scores range from 0 to 27 . The total scores were then categorized into 0-4 Minimal depression, 5-9 mild depression, 10-14 moderate depression, 15-19 moderately severe depression, and 20-27 severe depression (19). In this study, PHQ-9A was checked for reliability test, and it has been found to have Cronbach's alpha of 0.79 to assess depressive symptoms.

Adverse childhood experience was assessed by adverse childhood experience (ACEs). It addresses 10item ACEs under three categories: (1) abuse (2) neglect, and (3) household dysfunction. The higher the ACE Score indicates the greater the likelihood of exposure to adverse childhood experiences. The ACE questionnaire is reliable and valid in measuring childhood adverse experience that has been used in largescale ACE studies (20). In the current study, Cronbach's alpha was 0.71 .

Substance use was assessed by adopting questions from the Alcohol, Smoking, and Substance Involvement Screening Test (ASSIST). ASSIST was developed by the World Health Organization with fair reliability $(a=0.73)(21)$.

Oslo 3 Social Support Scale was used to know the level of social support towards students. The scale divides the level of social support into three as poor social support (3-8), moderate social support (9$11)$, and strong social support (12-14). The internal consistency of this tool (Cronbach's $a=0.91$ ) among university students in Nigeria (22).

The questionnaire was prepared in English and translated into the Amharic language and then backtranslated into English by two experts to ensure consistency and understandability. The Amharic version was used to collect the data. The instruments were pre-tested in $5 \%(n=39)$ of sample size. The training was given to supervisors by the principal investigator regarding the questioners' detail, methods of data collection, quality control, and ethical consideration. After data collection, the filled questionnaires were checked for completeness and consistency.

\section{Data analyses}


The data were cleaned, coded, and entered into the computer using Epi-Data version 3.1 and analyzed using Statistical Package for Social Sciences (SPSS) version 25. The presence of an association between dependent and independent variables was assessed using logistic regression. Variables with a p-value less than 0.25 at univariable logistic regression were entered into multivariable logistic regression. Statistical significance was considered at a p-value less than 0.05 , and the strength of association was estimated by odds ratio with a $95 \%$ confidence interval. Descriptive statistics including frequencies, percentages, and median was used to describe findings.

\section{Results}

\section{Socio demographic characteristics of participants}

A total of 756 (54.5.7\% female) students were participated, yielding a response rate of $96.8 \%$. The mean age of participants was 17.79 years (SD \pm 1.49$)$. Among all, 524 (69.3\%) were living with both parents (See Table 1 below). 
Table 1

Distribution of socio-demographic factors in public high school students at Bahir Dar city, $2021(n=756)$.

\begin{tabular}{|c|c|c|c|}
\hline Variables & Category & Frequency(756) & Percent (\%) \\
\hline \multirow[t]{2}{*}{ Sex } & Male & 344 & 45.5 \\
\hline & Female & 412 & 54.5 \\
\hline \multirow[t]{3}{*}{ Age } & $14-16$ & 141 & 18.7 \\
\hline & $17-19$ & 522 & 69.0 \\
\hline & $20-22$ & 93 & 12.3 \\
\hline \multirow[t]{4}{*}{ Religion } & Orthodox & 697 & 92.2 \\
\hline & Muslim & 37 & 4.9 \\
\hline & Protestant & 17 & 2.2 \\
\hline & Catholic & 5 & 0.7 \\
\hline \multirow[t]{4}{*}{ Educational level of respondents } & 9th & 217 & 28.7 \\
\hline & 10th & 214 & 28.3 \\
\hline & 11th & 164 & 21.7 \\
\hline & 12th & 161 & 21.3 \\
\hline \multirow[t]{2}{*}{ Residence of respondents } & Urban & 674 & 89.2 \\
\hline & Rural & 82 & 10.8 \\
\hline \multirow[t]{5}{*}{ Occupation of father } & Government employee & 233 & 30.8 \\
\hline & Merchant & 181 & 23.9 \\
\hline & Farmer & 196 & 25.9 \\
\hline & Daily labor & 39 & 5.2 \\
\hline & Other** & 107 & 14.2 \\
\hline \multirow[t]{5}{*}{ Occupation of mother } & Housewife & 463 & 61.2 \\
\hline & Merchant & 70 & 9.3 \\
\hline & Government employee & 98 & 13.0 \\
\hline & Farmer & 76 & 10.1 \\
\hline & Daily labor & 17 & 2.2 \\
\hline
\end{tabular}

*= Institution care, with husband and worker as maid $* *=$ car deliver, student, religious leader $* \star *=$ maid, student 


\begin{tabular}{|c|c|c|c|}
\hline Variables & Category & Frequency(756) & Percent (\%) \\
\hline & Other ${ }^{\star \star \star}$ & 32 & 4.2 \\
\hline \multirow[t]{4}{*}{ Educational level of father } & Unable to read and write & 105 & 13.9 \\
\hline & Read and write & 269 & 35.6 \\
\hline & Elementary school & 102 & 13.5 \\
\hline & High school and above & 280 & 37.0 \\
\hline \multirow[t]{4}{*}{ Educational level of mother } & Unable to read and write & 233 & 30.8 \\
\hline & Read and write & 233 & 30.8 \\
\hline & Elementary school & 112 & 14.8 \\
\hline & High school and above & 178 & 23.5 \\
\hline \multirow[t]{3}{*}{ Parental marital status } & Married & 624 & 82.5 \\
\hline & Divorced & 109 & 14.4 \\
\hline & Separated/widowed & 23 & 3.0 \\
\hline \multirow[t]{5}{*}{ Living status of respondents } & With both parents & 524 & 69.3 \\
\hline & With one parent & 106 & 14.0 \\
\hline & With relatives & 89 & 11.8 \\
\hline & Alone & 31 & 4.1 \\
\hline & Other* & 6 & 0.8 \\
\hline
\end{tabular}

\section{The Magnitude of Depression among public high school students}

The prevalence of depressive symptoms were found to be 149 (19.7\%) $(95 \% \mathrm{Cl}=16.9-22.6)$. Based on the severity scale, 101(13.4\%) had moderate depression, 38(5\%) had moderately severe depression, and $10(1.3 \%)$ of participants had severe depression.

\section{Adverse Childhood Experience among public school students}

Among the 756 students who participated in this study, 389 (51.5\%) of the participants answered yes to at least one or more questions among the total 10 questions of ACEs. According to the 3 categories of adverse childhood experience (ACE) from 344 female students, 103 (25.0\%) had been abused emotionally, physically, or sexually (See Table 2 below). 
Table 2: The cross-tabulation of ACE category by sex of public high school students at Bahir Dar city, $2021(n=756)$.

\begin{tabular}{lllll} 
ACE category & Girls $(\mathrm{N}=344), \%$ & Boys $(\mathrm{N}=412), \%$ & Overall $(\mathrm{N}=756), \%$ & P-value \\
\hline Abuse & \multicolumn{5}{l}{} & & \\
\hline Neglect & 25.0 & 31.7 & 28 & 0.042 \\
\hline Household dysfunction & 33.0 & 16.3 & 17.2 & 0.542 \\
\hline
\end{tabular}

\section{Health related factors of participants}

Of the total respondents of 756, 76 (10.1\%) have known medical illness. Likewise, 44 (5.8\%) have a family history of mental illness. Measurement by the Oslo 3-Item Social Support Scale showed that 297 $(39.3 \%)$ had poor social support, $288(38.1 \%)$ where had moderate social support and $171(22.6 \%)$ had strong social support.

\section{Substance use among high school students}

The life time use of substance was $18 \%$. One hundred one (13.4\%) of students used substances within 3 months (See Table 3 below).

Table 3: Description of substance use among high schools students at Bahir Dar city, $2021(n=756)$. 


\begin{tabular}{|c|c|c|c|}
\hline \multirow[t]{2}{*}{ Variables } & Response & Frequency & Percent \\
\hline & & & (\%) \\
\hline \multirow[t]{2}{*}{ Life time substance use } & No & 620 & 82.0 \\
\hline & Yes & 136 & 18.0 \\
\hline \multirow[t]{5}{*}{ Substances used in lifetime } & Khat & 24 & 3.2 \\
\hline & Cigarette & 16 & 2.1 \\
\hline & Alcohol & 89 & 11.8 \\
\hline & Marijuana & 3 & 0.4 \\
\hline & More than one substance & 4 & 0.5 \\
\hline \multirow[t]{2}{*}{ Substance use within 3 months } & No & 655 & 86.6 \\
\hline & Yes & 101 & 13.4 \\
\hline \multirow[t]{5}{*}{ Substances used within 3 months } & Khat & 17 & 2.2 \\
\hline & Cigarette & 15 & 2.0 \\
\hline & Alcohol & 61 & 8.1 \\
\hline & Marijuana & 5 & 0.7 \\
\hline & More than one substance & 3 & 0.4 \\
\hline
\end{tabular}

\section{Factors associated with depression}

The current study indicated that factors associated with depression are the sex of participants, have known medical conditions, social support, and childhood abuse, and neglect experience. The odds of developing depression was 2.40 times $(A O R=2.40,95 \% \mathrm{Cl}=1.56-3.68)$ higher in females compared to males. The odd of developing depression among participants of merchant mothers decrease by $61 \%$ as compared to participants of a housewife (mothers AOR $=0.39,95 \% \mathrm{Cl}=0.15-0.98$ ). The odds of having depression among respondents who have known medical conditions was 1.84 times higher than those without having known medical conditions $(A O R=1.84,95 \% \mathrm{Cl}=1.01-3.35)$. In this finding, the odds of having depression among respondents who have poor social support was 1.82 times $(A O R=1.82,95 \% \mathrm{Cl}$ $=1.01-3.30$ ) higher as compared to those who have strong social support. The odds of having depression among respondents who have a history of abuse were 2.07 times higher as compared to those who have no history of abuse ( $A O R=2.07,95 \% \mathrm{Cl}=1.36-3.28)$. The odds of having depression among respondents who have a history of neglect 2.57 times ( $A O R=2.57,95 \% \mathrm{Cl}=1.56-4.24)$ is higher as compared to those who have no history of neglect (see Table 4 below). 
Table 4

Bivariable and Multivariable binary logistic regression analysis showing association between depression and associated factors among public high school students, $2021(\mathrm{n}=756)$.

\begin{tabular}{|c|c|c|c|c|c|c|}
\hline \multirow[t]{2}{*}{ Explanatory variables } & \multirow{2}{*}{$\begin{array}{l}\text { Variables } \\
\text { category }\end{array}$} & \multicolumn{2}{|c|}{ Depression } & \multirow[t]{2}{*}{ COR $(95 \% \mathrm{Cl})$} & \multirow{2}{*}{$\begin{array}{l}\text { AOR, } \\
(95 \% \mathrm{Cl})\end{array}$} & \multirow{2}{*}{$\begin{array}{l}\mathrm{p} \text { - } \\
\text { value }\end{array}$} \\
\hline & & No & Yes & & & \\
\hline \multirow[t]{2}{*}{ Sex } & Male & 295 & 49 & 1.00 & 1.00 & \\
\hline & Female & 312 & 100 & $\begin{array}{l}1.93(1.32- \\
2.81)\end{array}$ & $\begin{array}{l}2.36(1.54- \\
3.61)\end{array}$ & $\overleftarrow{0.0001}$ \\
\hline \multirow[t]{3}{*}{ Living status } & With both parents & 438 & 86 & 1.00 & 1.00 & \\
\hline & With one parent & 80 & 26 & $\begin{array}{l}1.66(1.01- \\
2.73)\end{array}$ & $\begin{array}{l}1.26(0.60- \\
2.65)\end{array}$ & 0.536 \\
\hline & With non-parent & 89 & 37 & $\begin{array}{l}2.12(1.35- \\
3.31)\end{array}$ & $\begin{array}{l}1.76(0.99- \\
3.10)\end{array}$ & 0.051 \\
\hline \multirow[t]{3}{*}{ Occupation of father } & $\begin{array}{l}\text { Government } \\
\text { employee }\end{array}$ & 177 & 56 & 1.00 & 1.00 & \\
\hline & Merchant & 155 & 26 & $\begin{array}{l}0.53(0.32- \\
0.89)\end{array}$ & $\begin{array}{l}0.62(0.33- \\
1.16)\end{array}$ & 0.135 \\
\hline & Private employee & 275 & 67 & $\begin{array}{l}0.77(0.52- \\
1.15)\end{array}$ & $\begin{array}{l}0.73(0.40- \\
1.33)\end{array}$ & 0.299 \\
\hline \multirow[t]{4}{*}{ Occupation of mother } & Housewife & 378 & 85 & 1.00 & 1.00 & \\
\hline & Merchant & 64 & 6 & $\begin{array}{l}0.42(0.18- \\
0.99)\end{array}$ & $\begin{array}{l}0.38(0.15- \\
0.95)\end{array}$ & 0.039 \\
\hline & $\begin{array}{l}\text { Government } \\
\text { employee }\end{array}$ & 69 & 29 & $\begin{array}{l}1.87(1.14- \\
3.06)\end{array}$ & $\begin{array}{l}1.71(0.93- \\
3.15)\end{array}$ & 0.087 \\
\hline & Private employee & 96 & 29 & $\begin{array}{l}1.34(0.83- \\
2.17)\end{array}$ & $\begin{array}{l}1.11(0.63- \\
1.94)\end{array}$ & 0.721 \\
\hline \multirow[t]{4}{*}{$\begin{array}{l}\text { Educational level of } \\
\text { father }\end{array}$} & $\begin{array}{l}\text { High school and } \\
\text { above }\end{array}$ & 219 & 61 & 1.00 & 1.00 & \\
\hline & $\begin{array}{l}\text { Unable to read } \\
\text { and write }\end{array}$ & 79 & 26 & $1.18(0.70,2.00)$ & $\begin{array}{l}0.94(0.46- \\
1.90)\end{array}$ & 0.862 \\
\hline & Read and write & 223 & 46 & $0.74(0.46,1.13)$ & $\begin{array}{l}0.67(0.38- \\
1.18)\end{array}$ & 0.169 \\
\hline & $\begin{array}{l}\text { Elementary } \\
\text { school }\end{array}$ & 86 & 16 & $0.67(0.37,1.22)$ & $\begin{array}{l}0.82(0.40- \\
1.67)\end{array}$ & 0.578 \\
\hline $\begin{array}{l}\text { Parental marital } \\
\text { status }\end{array}$ & Married & 512 & 112 & 1.00 & 1.00 & \\
\hline
\end{tabular}

Hosmer and Lemeshow goodness of test $\mathrm{p}$-value $=0.95$ 


\begin{tabular}{|c|c|c|c|c|c|c|}
\hline & Unmarried & 95 & 37 & $\begin{array}{l}1.78(1.16- \\
2.74)\end{array}$ & $\begin{array}{l}1.38(0.72- \\
2.66)\end{array}$ & 0.338 \\
\hline \multirow[t]{2}{*}{ Abuse } & No & 467 & 77 & 1.00 & 1.00 & \\
\hline & Yes & 140 & 72 & $3.12(2.15,4.53)$ & $\begin{array}{l}2.02(1.28- \\
3.20)\end{array}$ & 0.003 \\
\hline \multirow[t]{2}{*}{ Neglect } & No & 534 & 92 & 1.00 & 1.00 & \\
\hline & Yes & 73 & 57 & $4.53(3.01,6.84)$ & $\begin{array}{l}2.78(1.70- \\
4.55)\end{array}$ & $\hat{0} .0001$ \\
\hline \multirow{2}{*}{$\begin{array}{l}\text { Household } \\
\text { dysfunction }\end{array}$} & No & 404 & 69 & 1.00 & 1.00 & \\
\hline & Yes & 203 & 80 & $2.31(1.60,3.32)$ & $\begin{array}{l}1.22(0.76- \\
1.98)\end{array}$ & 0.414 \\
\hline \multirow[t]{2}{*}{ Medical conditions } & No & 560 & 120 & 1.00 & 1.00 & \\
\hline & Yes & 47 & 29 & $2.88(1.74,4.76)$ & $\begin{array}{l}1.84(1.01- \\
3.33)\end{array}$ & 0.045 \\
\hline \multirow{2}{*}{$\begin{array}{l}\text { Family history of } \\
\text { mental illness }\end{array}$} & No & 579 & 133 & 1.00 & 1.00 & \\
\hline & Yes & 28 & 16 & $2.49(1.31,4.73)$ & $\begin{array}{l}0.96(0.43- \\
2.14)\end{array}$ & 0.925 \\
\hline \multirow[t]{2}{*}{ Current substance use } & No & 538 & 119 & 1.00 & 1.00 & \\
\hline & Yes & 69 & 30 & $\begin{array}{l}1.90(1.19- \\
3.05)\end{array}$ & $\begin{array}{l}1.16(0.64- \\
2.10)\end{array}$ & 0.624 \\
\hline \multirow[t]{3}{*}{ Social support } & Strong & 151 & 20 & 1.00 & 1.00 & \\
\hline & Moderate & 240 & 48 & $1.51(0.86,2.64)$ & $\begin{array}{l}1.49(0.82- \\
2.72)\end{array}$ & 0.193 \\
\hline & Poor & 216 & 81 & $2.83(1.67,4.82)$ & $\begin{array}{l}1.83(1.02- \\
3.31)\end{array}$ & 0.044 \\
\hline
\end{tabular}

\section{Discussion}

This study showed that the magnitude of depressive symptoms were $19.7 \%$ with $(95 \% \mathrm{Cl}=16.9 \%-22.6 \%$ ). This implies that depression among high school students is a public health concern because it leads to problems in everyday activities, educational impairment, comorbid psychoactive substance abuse, poor psychosocial outcomes, including lower social support, and risky reproductive and sexual practices (23). Adolescent depression increases the risk for subsequent depression later in life (5). The current study is consistent with the study reported $21.0 \%$ in Uganda (24), 21.2\% in Nigeria (25), 19.9\% in China (26), and $20.3 \%$ in India (27). The current study is lower than in studies reported $28 \%$ in Southwest Ethiopia (28), $45.9 \%$ in Kenya (29), 62.6\% in India (30), 25\% in Bangladesh (31), and $42.5 \%$ in Malaysia (32). It is higher 
than in studies which reported 14.9\% in Northern Ethiopia (17), 14.19\% in Thailand (33), 13.6\% in Korea (34), and $14.2 \%$ in Jamaica (35), and. Such a degree of difference in the prevalence of depression across the different parts of the world could originate from variations in the depression screening tools used, different study periods, and different populations. A study done in Malaysia used Depression, anxiety and stress scale (DASS) and a cross-sectional study in Korea used health-related behaviors 7 items. A study done in India and Jamaica used Beck's Depression Inventory-II and a cross-sectional study in Bangladesh and Thailand were used the Center of Epidemiologic studies depression scale (CES-D).

Moderate depression was $13.4 \%$ which was consistent with the study reported $11.4 \%$ in North Ethiopia (17), $16.1 \%$ in Nigeria (25), and $15.5 \%$ in India (27), and. The prevalence of moderately severe depression was found to be $5 \%$. It is consistent with the study reported $5.1 \%$ in Nigeria (25), and 3.7\% in India (27). The prevalence of severe depression was $1.3 \%$. This is consistent with findings reported $1.3 \%$ in Southwest Ethiopia (28), $1.1 \%$ in India (27).

Sex is one of the important factors contributing to depression $(11,17,36)$. The current study indicated that female participants had more than twofold $(A O R=2.40)$ odds of having depression as compared to male participants. This was supported by the study conducted in Ethiopia $(17,37)$, in India (38), in Malaysia (36), and Bangladesh (31). This may be due to different psychosocial stressors for females and male (39), involve hormonal differences, and females being more sensitive to interpersonal relationships problem (40).

Having known medical conditions is another factor that contributes to depression among high school students. The current study showed that participants who have known medical conditions had 1.83 times the odds of having depression than those who have no known medical conditions. This finding is consistent with a meta-analysis done in Germany (41). This may be due to having known medical conditions increase psychological stressors and affect cognitive mechanisms. In addition to this, physical illness can also cause depression directly by affecting brain functions (40).

During adolescence, social support is a strong protector against a wide range of adversities and is necessary for ensuring health development (41). In the current study odds of having depression among respondents who have poor social support was 1.82 times ( $\mathrm{AOR}=1.8,95 \% \mathrm{Cl}=1.01-3.30)$ higher as compared to those who have strong social support. This finding is consistent with studies done in Aksum (17), Jimma (37), and Kenya (29). This might be due to poor social support directly affecting social relationships and indirectly increasing the risk to face stressful circumstances (41).

Adverse childhood experiences (ACE) are another factor that contributes to depression (42). In the current study, the odds of having depression among respondents who have a history of abuse were twofold times higher as compared to those who have no history of abuse (AOR $=2.07,95 \% \mathrm{Cl}=1.30-3.30)$. This finding is consistent with the study done in Jimma (37), India (27), and meta-analysis studies done in China (43). Similarly, the odds of having depression among respondents who have a history of neglect 2.57 times $(\mathrm{AOR}=2.57,95 \% \mathrm{Cl}=1.64-4.51)$ is higher as compared to those who have no history of neglect. This finding is in concordance with studies done in Aksum (17), and Jimma (37). This may be 
due to the increased ACE leads to health risk behaviors such as substance abuse, alcoholism, drug abuse, and chronic disease even suicide (44). As research shows that chronic stress plays a critical role in the development of hippocampal and medial prefrontal cortex deficits, which are the well-documented neural abnormalities in depression (45).

The odds of developing depression among participants whose merchant mothers decrease by $61 \%$ as compared to participants of housewife mothers. This may be due to better income than housewives.

\section{Limitation of the study}

The study has some limitations. First, it is cross-sectional in design, so the direction of causality between depression and associated variables could not be inferred from the findings. Second, the recall bias may occur for questions about adverse childhood experience. Thirdly, the parenting style, family dynamics, self-esteem, and negative life events of the students were not assessed. Those variables may be important factors for depression among adolescent population.

\section{Conclusion}

The prevalence of depression among public high schools students in Bahir Dar city is high. One in five students was found to have depression in Bahir Dar city. The sex of participant, occupation of mother, having known medical conditions, lifetime substance use, social support, abuse, and neglect were significantly associated with depression. Schools need to institute routine mental health screening services and implement appropriate interventions to initiate and improve access to school-based mental health services, particularly for female students.

\section{Abbreviations}

ACE: Adverse Childhood Experiences, BDI II: Beck's Depression Inventory-II, CDI: Children Depression Inventory, CES-D: Children Epidemiologic Studies-Depression Scale, DASS: Depression, Anxiety and Stress Scale, DSM-5: Diagnostic and Statistical Manual of Mental Disorders, Fifth Edition, LMICs: Low-income and Middle-Income Countries, PHQ-9A: Patient Health Questionnarie-9 modified for adolescent, SPSS: Statistical Package for Social Sciences, USA: United State America, WHO: World Health Organization

\section{Declarations}

\section{Availability of data and materials}

The datasets used and/or analyzed during the current study are available from the corresponding authors on reasonable request.

\section{Acknowledgments}


We would like to thank Bahir Dar University for funding the study and the Bahir Dar city administration education office, and the school for all forms of non-financial support provided for the study. Furthermore, we extend our gratitude to data collectors, supervisors, and study participants for their time and effort.

\section{Funding}

Bahir Dar University.

\section{Authors' contributions}

DT developed the proposal, analyzed, and interpreted the data, and wrote the draft manuscript. TM, GA, and $\mathrm{HT}$ have revised the proposal, checked the data analysis, and revised the manuscript. DT TM, GA, and $\mathrm{HT}$ have read and approved the final manuscript.

\section{Ethics approval and consent to participate}

The ethics approval was obtained from the Institutional ethical review Board of Bahir Dar University College of medicine and health sciences and a permission letter were obtained from selected public high schools in Bahir City. Informed consent was obtained from participants. For students who are under 18 years old, parent consent forms were obtained from parents by written letter sent through their students before one week of data collection. The letter informs them of the purpose of the study, as well as provides them with the contact information of the principal investigator for any questions related to the study. The information from the individual participant was kept confidential.

\section{Consent for publication}

Not applicable.

\section{Competing interests}

The authors declare that they have no competing interests.

\section{References}

1. McGorry PD, Goldstone SD, Parker AG, Rickwood DJ, Hickie IB. Cultures for mental health care of young people: an Australian blueprint for reform. The Lancet Psychiatry. 2014;1(7):559-68.

2. Child NAMHCWo, Development AMHI, Deployment. Blueprint for change: Research on child and adolescent mental health. A report by the national advisory mental health council's workgroup on child and adolescent mental health intervention development and deployment. 2001.

3. World Health Organization. Fact sheets on Adolescent mental health 2020 [Available from: https://www.who.int/news-room/fact-sheets/detail/adolescent-mental-health.

4. Copeland WE, Alaie I, Jonsson U, Shanahan L. Associations of childhood and adolescent depression with adult psychiatric and functional outcomes. Journal of the American Academy of Child \& 
Adolescent Psychiatry. 2020.

5. Johnson D, Dupuis G, Piche J, Clayborne Z, Colman I. Adult mental health outcomes of adolescent depression: a systematic review. Depression and anxiety. 2018;35(8):700-16.

6. National Institute of Mental Health. Transforming the understanding and treatment of mental illnesses [o]. Available from: https://www.nimh.nih.gov/health/statistics/majordepression\#part_155028.

7. Thapar A, Collishaw S, Pine DS, Thapar AK. Depression in adolescence. The Lancet. 2012;379(9820):1056-67.

8. World Health Organization. Investing in mental health 2003 [Available from: https://apps.who.int/iris/handle/10665/42823.

9. World Health Organization. Fact sheets on adolescents risk factors and solutions 2021 [Available from: https://www.who.int/news-room/fact-sheets/detail/adolescents-health-risks-and-solutions.

10. Gotlib IH, Hammen CL. Handbook of depression: Guilford Press; 2008.

11. health. Nlom. Transforming the understanding and treatment of mental illnesses [Available from: https://www.nimh.nih.gov/health/statistics/major-depression.shtml\#part_155028.

12. Jörns-Presentati A, Napp A-K, Dessauvagie AS, Stein DJ, Jonker D, Breet E, et al. The prevalence of mental health problems in sub-Saharan adolescents: A systematic review. Plos one. 2021;16(5):e0251689.

13. Healthline. Adolescent Depression [Available from: https://www.healthline.com/health/adolescentdepression.

14. Demoze MB, Angaw DA, Mulat H. Prevalence and associated factors of depression among orphan adolescents in Addis Ababa, Ethiopia. Psychiatry journal. 2018;2018.

15. Shiferaw G, Bacha L, Tsegaye D. Prevalence of depression and its associated factors among orphan children in orphanages in Ilu Abba Bor Zone, South West Ethiopia. Psychiatry journal. 2018;2018.

16. Abebe H, Shumet S, Nassir Z, Agidew M, Abebaw D. Prevalence of Depressive Symptoms and Associated Factors among HIV-Positive Youth Attending ART Follow-Up in Addis Ababa, Ethiopia. AIDS Research and Treatment. 2019;2019:4610458.

17. Tirfeneh E, Srahbzu M. Depression and its association with parental neglect among adolescents at governmental high schools of Aksum Town, Tigray, Ethiopia, 2019: a cross sectional study. Depression research and treatment. 2020;2020.

18. Seid S. Prevalence of Depression among Adolescents and Association of Parental Neglect on Depression in Governmental Preparatory Schools in Addis Ababa. Ethiopia, Addis Abeba Universty. 2017.

19. Johnson JG, Harris ES, Spitzer RL, Williams JB. The patient health questionnaire for adolescents: validation of an instrument for the assessment of mental disorders among adolescent primary care patients. The Journal of adolescent health: official publication of the Society for Adolescent Medicine. 2002;30(3):196-204. 
20. Karatekin C, Hill M. Expanding the original definition of adverse childhood experiences (ACEs). Journal of child \& adolescent trauma. 2019;12(3):289-306.

21. Onifade P, Bello A, Abiodun O, Sotunsa J, Ladipo O. Psychometric properties of alcohol smoking and substance involvement screening test (Assist V3. 0) among university students. J Addict Behav Ther Rehab. 2014;3(3):2-7.

22. Abiola T, Udofia 0 , Zakari M. Psychometric properties of the 3-item oslo social support scale among clinical students of Bayero University Kano, Nigeria. Malaysian Journal of Psychiatry. 2013;22(2):32-41.

23. Kumar KS, Srivastava S, Paswan S, Dutta AS. Depression-symptoms, causes, medications and therapies. The Pharma Innovation. 2012;1(3, Part A):37.

24. Nalugya-Sserunjogi J, Rukundo GZ, Ovuga E, Kiwuwa SM, Musisi S, Nakimuli-Mpungu E. Prevalence and factors associated with depression symptoms among school-going adolescents in Central Uganda. Child and adolescent psychiatry and mental health. 2016;10(1):39.

25. Fatiregun A, Kumapayi T. Prevalence and correlates of depressive symptoms among in-school adolescents in a rural district in southwest Nigeria. Journal of Adolescence. 2014;37(2):197-203.

26. Radovic A, Moreno MA. Treatment Options for Adolescent Depression. JAMA pediatrics. 2019;173(3):300-.

27. Singh MM, Gupta M, Grover S. Prevalence \& factors associated with depression among schoolgoing adolescents in Chandigarh, north India. The Indian journal of medical research. 2017;146(2):205-15.

28. Girma S, Tsehay M, Mamaru A, Abera M. Depression and its determinants among adolescents in Jimma town, Southwest Ethiopia. Plos one. 2021;16(5):e0250927.

29. Osborn TL, Venturo-Conerly KE, Wasil AR, Schleider JL, Weisz JR. Depression and anxiety symptoms, social support, and demographic factors among Kenyan high school students. Journal of Child and Family Studies. 2020;29(5):1432-43.

30. Sinha S, Patil MS, Viveki R, Halki S. Prevalence of depression among school going adolescents in an urban area of Karnataka, India: a cross sectional study. International journal of community medicine and public health (Gujarat). 2020;7(5):1790-3.

31. Khan A, Ahmed R, Burton NW. Prevalence and correlates of depressive symptoms in secondary school children in Dhaka city, Bangladesh. Ethnicity \& Health. 2020;25(1):34-46.

32. Latiff LA, Tajik E, Ibrahim N, Abubakar AS, Ali SSBA. Depression and its associated factors among secondary school students in Malaysia. Southeast Asian Journal of Tropical Medicine and Public Health. 2016;47(1):131.

33. Chaveepojnkamjorn W, Pichainarong N, Adthasangsri V, Sativipawee P, Prasertsong C. Depression and its associated factors among Senior High School students in Nonthaburi Province, Thailand: a cross-sectional study. Journal of Public Health in Developing Countries. 2016;2(3):224-34.

34. Yun J-Y, Chung H, Sim J-a, Yun YH. Prevalence and associated factors of depression among Korean adolescents. PloS one. 2019;14(10):e0223176. 
35. Ekundayo OJ, Dodson-Stallworth J, Roofe M, Aban IB, Kempf MC, Ehiri JE, et al. Prevalence and correlates of depressive symptoms among high school students in Hanover, Jamaica. TheScientificWorldJOURNAL. 2007;7.

36. Sahril N, Yaacob N, Ahmad N, Abdullah S, Naidu B, Aris T. Depression Severity and Its Associated Factors Among School-Going Adolescents in Malaysia. J Dep Anxiety. 2019;8(350):2167-1044.19.

37. Tsehay M, Necho M, Mekonnen W. The Role of Adverse Childhood Experience on Depression Symptom, Prevalence, and Severity among School Going Adolescents. Depression Research and Treatment. 2020;2020:5951792.

38. madmoli y, madmoli m, Qashqaei nezhad n, Bosak S. Prevalence of depression and associated factors in adolescents of masjed-soleyman. Iranian Journal of Pediatric Nursing. 2016;2(4):22 - 7.

39. Bartels M, Cacioppo JT, van Beijsterveldt TC, Boomsma DI. Exploring the association between wellbeing and psychopathology in adolescents. Behavior genetics. 2013;43(3):177-90.

40. Kendler KS, Thornton LM, Gardner CO. Genetic risk, number of previous depressive episodes, and stressful life events in predicting onset of major depression. American Journal of Psychiatry. 2001;158(4):582-6.

41. Demaray MK, Malecki CK. Critical levels of perceived social support associated with student adjustment. School psychology quarterly. 2002;17(3):213.

42. Thomson $P$, Jaque SV. Adverse childhood experiences (ACE) and adult attachment interview (AAI) in a non-clinical population. Child Abuse \& Neglect. 2017;70:255-63.

43. Tang X, Tang S, Ren Z, Wong DFK. Psychosocial risk factors associated with depressive symptoms among adolescents in secondary schools in mainland China: a systematic review and meta-analysis. Journal of affective disorders. 2020;263:155-65.

44. Wiehn J, Hornberg C, Fischer F. How adverse childhood experiences relate to single and multiple health risk behaviours in German public university students: a cross-sectional analysis. BMC Public Health. 2018;18(1):1005.

45. Belleau EL, Treadway MT, Pizzagalli DA. The impact of stress and major depressive disorder on hippocampal and medial prefrontal cortex morphology. Biological psychiatry. 2019;85(6):443-53.

\section{Figures}




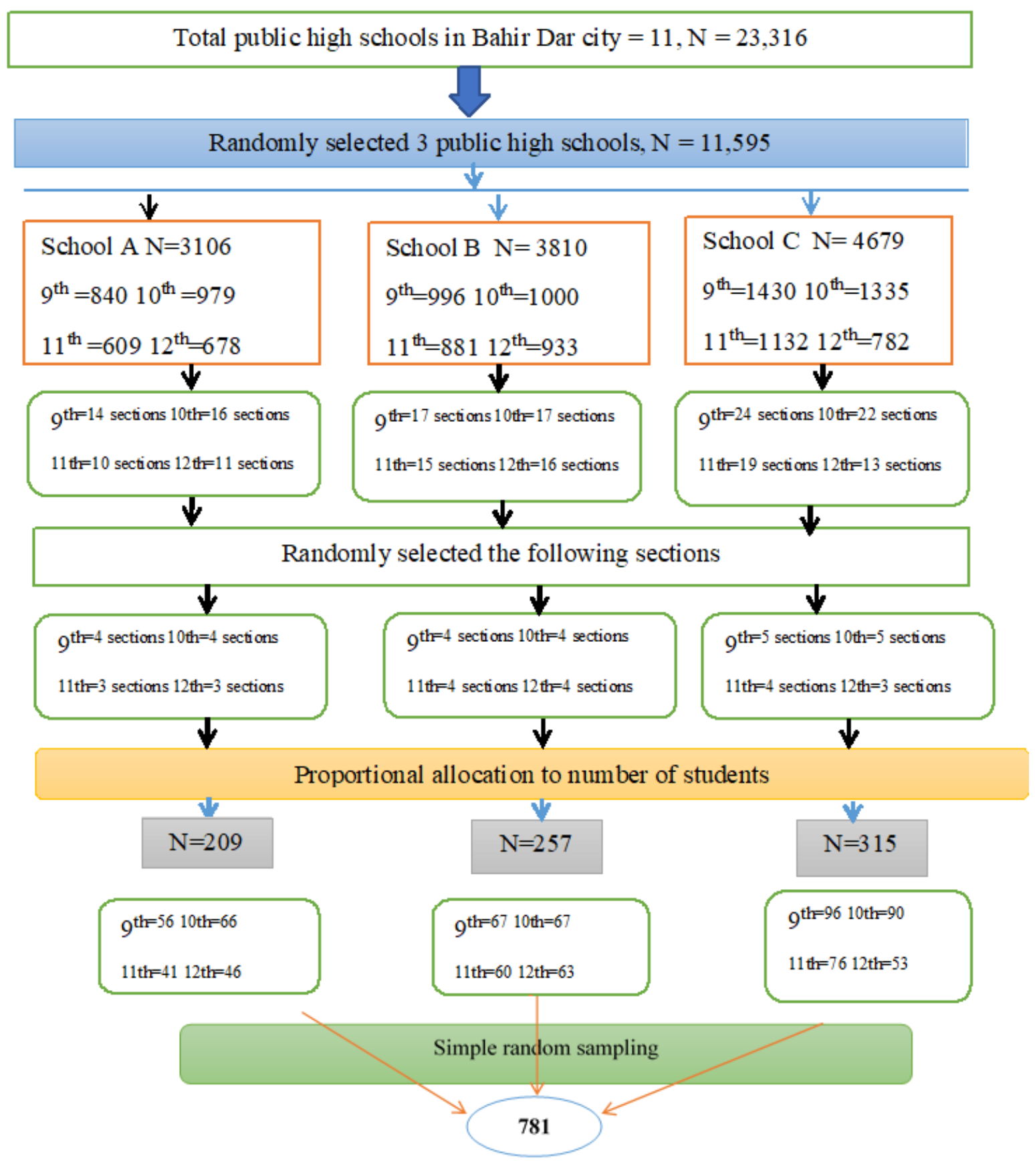

\section{Figure 1}

Schematic representation of the sampling procedure among public high school students in Bahir Dar city, Northwest Ethiopia, 2021. 